\title{
Study of Direct Torque Controlled 3-phase SCIM with Two and Three-level Inverters using ST-DTC and FR-DTC scheme
}

\author{
Pradeep Ranjan Tripathy \\ Department of Electrical Engg, \\ KIIT Polytechnic, KIIT, 751024 \\ Bhubaneswar, India \\ pradeeptripathy_10@yahoo.co.in
}

\author{
Bibhu Prasad Panigrahi \\ Department of Electrical Engg \\ Indira Gandhi Institute of Technology, Sarang. 759146 \\ Dhenkanal, India \\ bibhu89@yahoo.com
}

\begin{abstract}
DTC control strategy helps to obtain fast and smooth control in 3-phase induction motors. It does not depend upon the machine parameters and transformation of reference frames. Various control strategies on the Direct Torque Control (DTC) scheme have been carried out in the present study. The suggested scheme is meant for designing the low cost control circuit for DTC implementation on 3-phase SCIM. Three schemes with two types of inverters have been simulated in MATLAB (Simulink) environment and the THD ratio in each case has been studied along with Fast Fourier Transform (FFT) tools to compare the advantages.
\end{abstract}

Keywords-FOC; ST-DTC; FR-DTC; 2LI; 3LI; six sectors; twelve sectors.

\section{INTRODUCTION}

Induction motors with conventional control schemes used in common industrial drives are not capable of providing fast and smooth torque variation, due to the inherent characteristics of the induction motor along with the complex, non linear and time varying dynamics. The inaccessibility of some states and outputs makes the input voltage prediction more difficult. Though more effective control strategies in DC motors have been established, safety concerns related to flammability render these impracticable in many areas. The use of induction motor has thus become a popular practice, only after the invention of Field Oriented Control (FOC) in the 1970s. The FOC scheme decouples the stator current into torque and flux producing components so as to control the induction motor like a DC motor. FOC suffers from limitations arising from computationally intensive design procedures. The dependence of this scheme on most machine parameters and reference frame transformations contribute to these difficulties [1, 7]. The Direct Torque Control (DTC) scheme postulated in 1980's [2, 3] simplified the dynamic and steady state torque control. Transformation of the reference frame is not required in this scheme. The stator resistance is enough to calculate the stator flux and torque. The torque control is performed keeping stator flux intact and changing the torque angle by acceleration or deceleration of the stator linked flux, by selecting the optimum voltage vector. The optimum voltage vector is derived from a switching table, based on the flux and torque errors and the angular position of the stator linked flux in space.

Implementation of this method is normally performed using high speed processors, [4-6, 8-10] which is a costly affair. Low cost analog circuits can also be implemented for the DTC scheme, being economical for small industrial sectors $[11,12]$. Torque control is possible in two quadrant operation using low cost analog circuits [13-15]. The common drawback of this scheme is the ripple in current and torque. In present context, a descriptive study has been carried out for the comparative study of current, flux and torque response referred to a varying stepped torque command. The study is elaborated with the use of two level VSI and diode clamped three level inverter following a Switching Table based DTC (ST-DTC) scheme and Fuzzy Rule based DTC (FR-DTC) scheme. All simulations have been carried out in MATLAB Simulink environment. The switching look-up table and sector determination table have been realised using the state flow chart of the ST-DTC scheme used for two and three level VSI. The Fuzzy logic based lookup table uses twelve sectors to obtain better performance in torque and current. Overall, the present study emphasizes on the use of the control scheme that can be implemented practically in various environments. An improvement of response is noticed through high level inverter use.

\section{PRINCIPLE OF DTC}

\section{A. Using two level inverter}

The stator terminal voltage and line currents are sensed and transformed to d-q stationary frame [14, 15]. Two axis stator linked flux $\psi_{\mathrm{ds}}$ and $\psi_{\mathrm{qs}}$ are estimated by integrating the emfs, which are obtained after compensating stator resistance voltage drop from two axes stator voltages. Torque is calculated using $\mathrm{d}-\mathrm{q}$ axis flux and current components. The instantaneous angular position of stator linked flux is determined digitally within six sectors in space $[12,14]$. The absolute value of flux and the estimated torque are compared with their respective command values to obtain error signals. Both error signals are inspected by two prefixed band limits to yield control signals. The torque control signal is of three levels $(1,0,-1)$ and the flux 
control signal is of two levels $(1,0)$. The look-up table (switching table) decides the switching pattern for 2-level VSI $[14,15]$. It uses three inputs, torque and flux control signal along with the dwelling position of stator flux in sextant.

The switching table decides the optimum switching voltage vector, based on acceleration or deceleration of torque and flux corresponding to command value. In the FR-DTC scheme, a fuzzy controller replaces the hysteresis bands used in ST-DTC scheme [15]. The flux and torque errors obtained comparing the respective command values are used as input state variables for the fuzzy controller. The fuzzy controller uses the angular dwelling position of stator flux as the third input state variable (Figure 1).

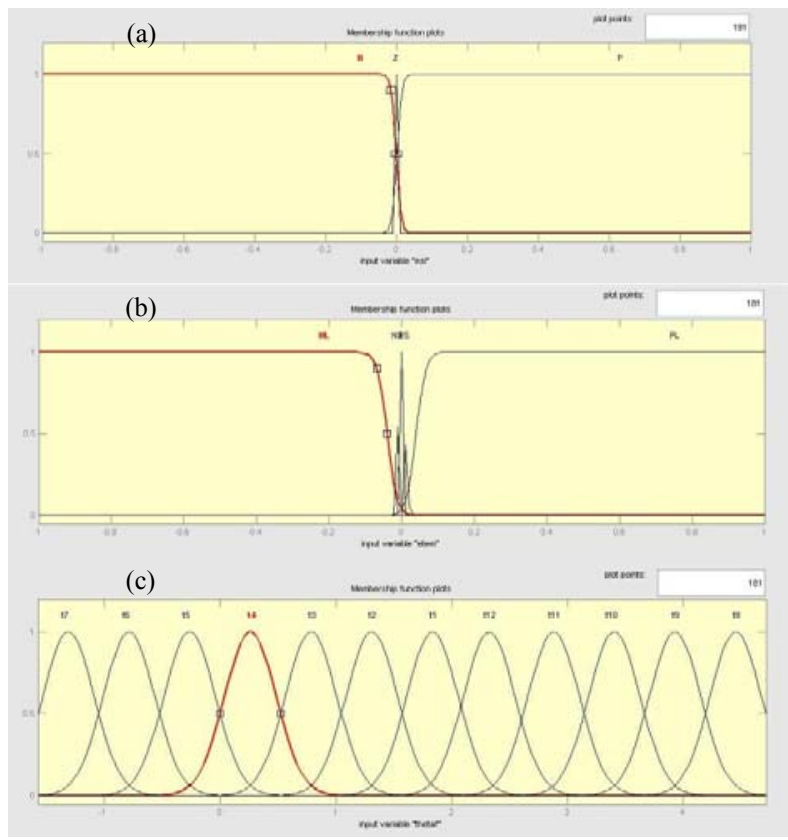

Fig. 1. (a) Flux error membership function (b) Torque error membership function (c) Twelve angular dwelling position of stator flux

The stator flux error variable is represented by three membership functions $\mathrm{N}, \mathrm{Z}$ and $\mathrm{P}$. The three membership functions denote a decrease of the stator flux, no change of flux and an increase of the flux. The torque error is calculated by comparing the calculated electromagnetic torque with the desired command torque. The torque error variable is denoted by five membership functions: NL, NS, Z, PS and PL [15]. Corresponding functions represent a large or small decrease in torque, no change in torque and a small or large increase in torque. The angular position of the stator flux is defined in twelve sectors in the sextant. Each sector of the ST-DTC scheme is divided into two parts to facilitate the accurate judgement of call for voltage vector. Considering the stator flux to dwell in the first $60^{\circ}$ in the air gap space and assuming the torque and flux errors to be positive, the demanding voltage phasor will tend to increase the torque. The voltage demand can be satisfied with the voltage phasor in sector I or VI. If the flux is in the first $30^{\circ}$ of sector I, then any one of the above voltage vectors can meet the purpose. When it is in the second $30^{\circ}$, the voltage phasor corresponding to sector VI of sextant provides the advancement of the flux vector. Hence, 180 rules are defined to decide the optimum switching vector. Mamdani method is used for defuzzification. The fuzzy controller gives three crisp outputs corresponding to the three legs of a 2-level VSI.

\section{B. Using Three Level Inverter}

The 3-level inverter needs a lower switching frequency, compared to the 2-level inverter, to achieve the desired sinusoidal voltage output. Hence, current harmonic decreases and efficient utilisation of energy is obtained. In each phase there are two complementary switching pairs. While one of the switch pair is turned on, the other complementary switch pair remains turned off. In 3-level inverter a set of two switches turns on at any given time. In a 3-level inverter there are 3-evel output voltage and 5-level output line voltage. The possible switching state of any leg is $\mathrm{S}_{1}-\mathrm{S}_{2}, \mathrm{~S}_{2}-\mathrm{S}_{1}$ ' and $\mathrm{S}_{1}$ ' $-\mathrm{S}_{2}$ ' providing output voltages $2 \mathrm{~V}_{\mathrm{dc}}, \mathrm{V}_{\mathrm{dc}}, 0$ respectively. Hence, the possible switching states in three phase 3 -level inverter are $3^{3}=27$. Out of these 27 states, 24 states are active and 3 states are zero state vectors. The active vectors are of three types, such as 6 long vectors, 6 medium vectors and 12 short vectors. The long vectors are (002), (020), (022), (200), (220) and (202) having magnitude of $\sqrt{ }\left(\mathrm{V}_{\mathrm{q}}^{2}+\mathrm{V}_{\mathrm{d}}^{2}\right)=4 \mathrm{~V}_{\mathrm{dc}} / 3$. The medium vectors $(012)$, (021), (120), (210), (102) and (201) have magnitude of $2 \mathrm{~V}_{\mathrm{dc}} / \sqrt{3}$ and the rest 12 short vectors have magnitude of $2 \mathrm{Vdc} / 3$.

The air gap space is divided into twelve sectors (Figure 2), according to adjacent medium and long vectors each spreads with $30^{\circ}$. Instantaneous angular position of the stator flux is determined digitally as in Table I. Signal $A_{1}, A_{2}$ and $A_{3}$ denote the angular position of stator flux. The signals are true if the absolute value of the ratio $\psi_{\mathrm{qs}} / \psi_{\mathrm{ds}}$ is greater than or equal to tan (pi/2), $\tan (\mathrm{pi} / 4)$ and $\tan (5 . \mathrm{pi} / 2)$ respectively. Positive value of $\psi_{\mathrm{qs}}$ and $\psi_{\mathrm{ds}}$ denote 1 , otherwise 0 . Thus the dwelling position of stator linked flux is identified by the generating signal $S_{\theta}$. The absolute value of flux and the calculated torque are compared with their respective commands and generate the errors, which are further inspected by prefixed hysteresis bands to yield the flux control signal $\left(\mathrm{S}_{\psi}\right)$ and the torque control signal $\left(\mathrm{S}_{\mathrm{T}}\right)$.

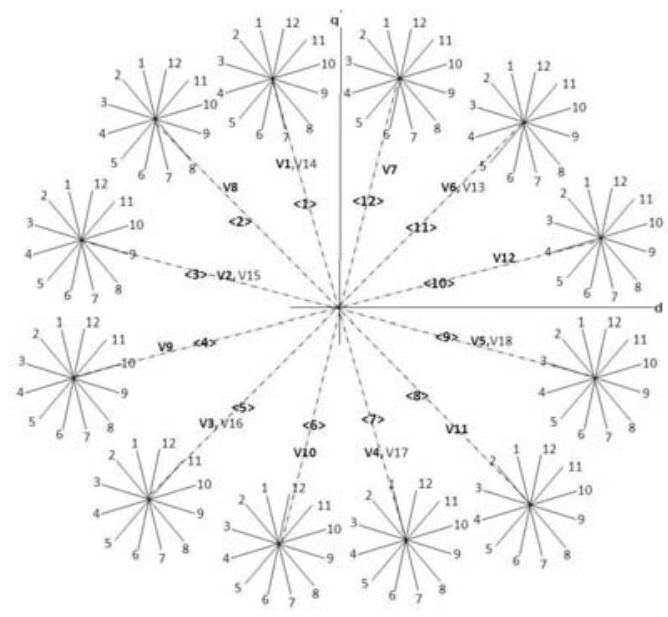

Fig. 2. Twelve sectors with switching vectors 
TABLE I. DTC SWITCHING TABLE FOR 3-LEVEL INVERTER

\begin{tabular}{|c|c|c|c|c|c|c|c|c|c|c|c|c|c|}
\hline \multirow[t]{2}{*}{$\mathbf{S}_{\psi}$} & \multirow[t]{2}{*}{$\mathbf{S}_{\mathrm{T}}$} & \multicolumn{12}{|c|}{$\mathbf{S}_{\boldsymbol{\theta}}$} \\
\hline & & $<1>$ & $<2>$ & $<3>$ & $<4>$ & $<5>$ & $<6>$ & $<7>$ & $<8>$ & $\langle 9\rangle$ & $<10>$ & $<11>$ & $<12>$ \\
\hline \multirow{2}{*}{1} & \multirow{2}{*}{1} & $\mathrm{~V}_{2}(220)$ & $\mathrm{V}_{9}(120)$ & $\mathrm{V}_{3}(020)$ & $\mathrm{V}_{10}(021)$ & $\mathrm{V}_{4}(022)$ & $\mathrm{V}_{11}(012)$ & $\mathrm{V}_{5}(002)$ & $\mathrm{V}_{12}(102)$ & $\mathrm{V}_{6}(202)$ & $\mathrm{V}_{7}(201)$ & $\mathrm{V}_{1}(200)$ & $\mathrm{V}_{8}(210)$ \\
\hline & & $\mathrm{V}_{8}(210)$ & $\mathrm{V}_{2}(220)$ & $\mathrm{V}_{9}(120)$ & $\mathrm{V}_{3}(020)$ & $\mathrm{V}_{10}(021)$ & $\mathrm{V}_{4}(022)$ & $\mathrm{V}_{11}(012)$ & $\mathrm{V}_{5}(002)$ & $\mathrm{V}_{12}(102)$ & $\mathrm{V}_{6}(202)$ & $\mathrm{V}_{7}(201)$ & $\mathrm{V}_{1}(200)$ \\
\hline 1 & 0 & $\mathrm{~V}_{26}(111)$ & $\mathrm{V}_{27}(222)$ & $\mathrm{V}_{25}(000)$ & $\mathrm{V}_{26}(111)$ & $\mathrm{V}_{27}(222)$ & $\mathrm{V}_{25}(000)$ & $\mathrm{V}_{26}(111)$ & $\mathrm{V}_{27}(222)$ & $\mathrm{V}_{25}(000)$ & $\mathrm{V}_{26}(111)$ & $\mathrm{V}_{27}(222)$ & $\mathrm{V}_{25}(000)$ \\
\hline \multirow[b]{2}{*}{1} & \multirow[b]{2}{*}{-1} & $\mathrm{~V}_{6}(202)$ & $\mathrm{V}_{7}(201)$ & $\mathrm{V}_{1}(200)$ & $\mathrm{V}_{8}(210)$ & $\mathrm{V}_{2}(220)$ & $\mathrm{V}_{9}(120)$ & $\mathrm{V}_{3}(020)$ & $\mathrm{V}_{10}(021)$ & $\mathrm{V}_{4}(022)$ & $\mathrm{V}_{11}(012)$ & $\mathrm{V}_{5}(002)$ & $\mathrm{V}_{12}(102)$ \\
\hline & & $\mathrm{V}_{7}(201)$ & $\mathrm{V}_{1}(200)$ & $\mathrm{V}_{8}(210)$ & $\mathrm{V}_{2}(220)$ & $\mathrm{V}_{9}(120)$ & $\mathrm{V}_{3}(020)$ & $\mathrm{V}_{10}(021)$ & $\mathrm{V}_{4}(022)$ & $\mathrm{V}_{11}(012)$ & $\mathrm{V}_{5}(002)$ & $\mathrm{V}_{12}(102)$ & $\mathrm{V}_{6}(202)$ \\
\hline \multirow{2}{*}{0} & \multirow{2}{*}{1} & $\mathrm{~V}_{3}(020)$ & $\mathrm{V}_{10}(021)$ & $\mathrm{V}_{4}(022)$ & $\mathrm{V}_{11}(012$ & $\mathrm{V}_{5}(002)$ & $\mathrm{V}_{12}(102)$ & $\mathrm{V}_{6}(202$ & $\mathrm{V}_{7}(2 \mathrm{C}$ & $\mathrm{V}_{1}(200)$ & $\mathrm{V}_{8} \mathrm{C}$ & $\mathrm{V}_{2}($ & $\mathrm{V}_{9}(120)$ \\
\hline & & $\mathrm{V}_{10}(021)$ & $\mathrm{V}_{4}(022)$ & $\mathrm{V}_{11}(012)$ & $\mathrm{V}_{5}(002)$ & $\mathrm{V}_{12}(102)$ & $\mathrm{V}_{6}(202)$ & $\mathrm{V}_{7}(201)$ & $\mathrm{V}_{\mathrm{l}}(200)$ & $\mathrm{V}_{8}(210)$ & $\mathrm{V}_{2}(220)$ & $\mathrm{V}_{9}(120)$ & $\mathrm{V}_{3}(020)$ \\
\hline 0 & 0 & $\mathrm{~V}_{25}(000)$ & $\mathrm{V}_{26}(111)$ & $\mathrm{V}_{27}(222)$ & $\mathrm{V}_{25}(000)$ & $\mathrm{V}_{26}(111)$ & $\mathrm{V}_{27}(222)$ & $\mathrm{V}_{25}(000)$ & $\mathrm{V}_{26}(111)$ & $\mathrm{V}_{27}(222)$ & $\mathrm{V}_{25}(000)$ & $\mathrm{V}_{26}(111)$ & $\mathrm{V}_{27}(222)$ \\
\hline \multirow{2}{*}{0} & \multirow{2}{*}{-1} & $\mathrm{~V}_{5}(002)$ & $\mathrm{V}_{12}(102)$ & $\mathrm{V}_{6}(202)$ & $\mathrm{V}_{7}(201)$ & $\mathrm{V}_{1}(200)$ & $\mathrm{V}_{8}(210)$ & $\mathrm{V}_{2}(220)$ & $\mathrm{V}_{9}(120)$ & $\mathrm{V}_{3}(020)$ & $\mathrm{V}_{10}(021)$ & $\mathrm{V}_{4}(022)$ & $\mathrm{V}_{11}(012)$ \\
\hline & & $\mathrm{V}_{11}(012)$ & $\mathrm{V}_{5}(002)$ & $\mathrm{V}_{12}(102)$ & $\mathrm{V}_{6}(202)$ & $\mathrm{V}_{7}(201)$ & $\mathrm{V}_{1}(200)$ & $\mathrm{V}_{8}(210)$ & $\mathrm{V}_{2}(220)$ & $\mathrm{V}_{9}(120)$ & $\mathrm{V}_{3}(020)$ & $\mathrm{V}_{10}(021)$ & $\mathrm{V}_{4}(022)$ \\
\hline
\end{tabular}

The switching table (Table I) is formulated based on the angular position of the stator linked flux in space and the requirement of acceleration or deceleration of flux and torque, maintaining a constant magnitude of stator flux. Hence, the lookup table decides the optimum switching vector for the three-level VSI with the help of the three inputs $S_{\psi}, S_{T}$, and $S_{\theta}$. Based on the dwelling position of the stator flux in a particular sector the digital control signals of flux and torque indicate the required voltage state for switching. For example, while the stator flux dwells in sector $<1>$ and both the flux and torque signal are 1 , then four possible of switching states may be selected. Those are long vector $\mathrm{V}_{2}(220)$, medium vector $\mathrm{V}_{8}$ (210), the short vector $V_{15}$ (110) and its redundancies for increasing in both torque and flux. The switching vectors lie in sector $\langle 2>$ and sector $<3>$. Similarly if flux and torque control signals are 0 and 1 , voltage vectors $\mathrm{V}_{3}(020), \mathrm{V}_{10}(021), \mathrm{V}_{16}$ (010) and its redundancy may be selected. The redundant vectors are the switching states from $V_{13}$ to $V_{24}$ respectively. When the torque control signal is zero, no change in torque is needed and a zero vector, $\mathrm{V}_{25}(000), \mathrm{V}_{26}(111)$ or $\mathrm{V}_{27}(222)$, is selected. The possible look up table is shown in Table I. Logic 2 stands for on condition of both upper arm switch, logic 1 for on condition of middle two switches and logic 0 for on condition of lower switches. The optimum switching vector for the corresponding inverter is decided by the switching table to achieve the required torque control. The switching states are depicted in Figure 3.

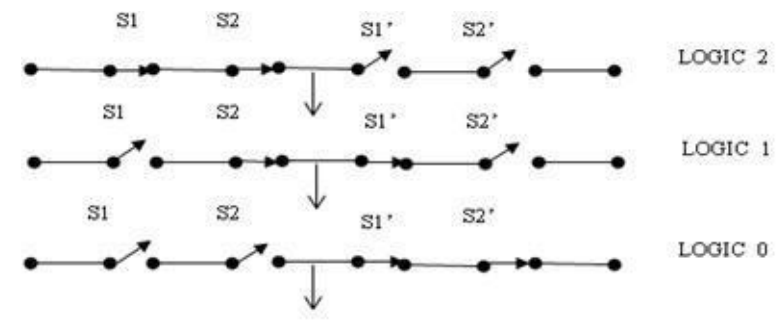

Fig. 3. Switching Logic States in 3-Level Inverter

\section{SIMULATION STUDY}

Both ST-DTC and FR-DTC schemes using two and three level inverters have been simulated in the MATLAB Simulink environment. The machine parameters of the 3-phase, $0.75 \mathrm{~kW}$, $50 \mathrm{~Hz}$, star connected induction motor are as follows: $\mathrm{V}_{\mathrm{LL}}=415$
$\mathrm{V}, \quad \mathrm{R}_{\mathrm{a}}=16.575 \Omega, \quad \mathrm{R}_{\mathrm{r}}=5.2183 \quad \Omega, \quad \mathrm{L}_{\mathrm{ls}}=\mathrm{L}_{\mathrm{lr}}=0.0404558 \quad \mathrm{H}$, $\mathrm{L}_{\mathrm{m}}=0.5393595 \mathrm{H}, \mathrm{P}=4, \mathrm{~J}=0.0048742 \mathrm{~kg}-\mathrm{m}^{2}, \mathrm{~B}=0.000001 \mathrm{Nm}-\mathrm{s}$. The line value of stator voltage and current are sensed to transform into $d-q$ component of voltage and current. Using flux and torque estimator, flux and torque are calculated after compensating the stator resistance drop from the d-q stator voltage [13]. The absolute values of flux and torque are compared with their respective command values to obtain the corresponding errors. The flux command has been considered as the rated flux $(1.00184 \mathrm{~Wb})$ and the rated torque as 5.0618 $\mathrm{N}-\mathrm{m}$. The simulation has been carried out with a variable two quadrant torque command with an equal time interval of $0.06 \mathrm{~s}$. The initial step command is $30 \%$ for the first interval, which changes to $60 \%$ and then to $30 \%$ of rated torque in succeeding time intervals, and finally falls to zero. The negative torque command is set to 0.24 second.

The errors obtained are compared in their respective hysteresis bands and control signals $\mathrm{S}_{\psi}$ and $\mathrm{S}_{\mathrm{T}}$ are generated. Both of these control signals along with the position of the stator linked flux $\mathrm{S}_{\theta}$ are judged by the distinguished lookup table meant for two-level and three-level inverters to obtain the optimum switching vectors. The flux and torque errors are directly used as the state variable inputs in the fuzzy controller of the FR-DTC scheme. The angular position of the stator linked flux is used as the third state variable. The scheme has been simulated for two and three level inverters. All the three state variables are processed by the fuzzy controller, using 180 fuzzy rules. The crisp outputs of the fuzzy controller are utilised for switching the inverters after generating its complement for lower switch of any inverter leg. The simulation has been performed for all three cases i.e. ST-DTC for two and 3-level inverters and FR-DTC for 2-level inverter.

The x-y plotting of the d-q flux (Figure 4) is of circular shape for all schemes proving the spatial relation, and the magnitude versus time shows a constant magnitude of $1.00184629 \mathrm{~Wb}$, (Figure 5a) at variable torque command in two quadrants. It is found that the flux ripple reduces with the use of high level inverter. The plot in Figure 5c shows the dwelling position of the stator flux. It varies in the sextant within $-\pi / 2$ to $3 \pi / 2$ radians and its direction changes with a change in torque command. It is shown that the magnitude of stator flux remains intact with a variation of torque command either in forward or reverse direction. The two axis flux $\psi_{\mathrm{qs}}$ and $\psi_{\mathrm{ds}}$ maintain $\pi / 2$ radian phase difference as shown in Figure 5. 
The variation of current in each scheme has been depicted in Figures 7 and 8 . The current settles to steady state comparatively quickly in the 3 level inverter based STDTC (3LISTDTC) scheme with least dynamic amplitude. The two axes current resemble the circular shape in $x-y$ plotting and the frequency and magnitude changes along with the change of torque command. When motor changes its motion from forward to reverse the $\pi / 2$ lagging property of the two axes current reverses.

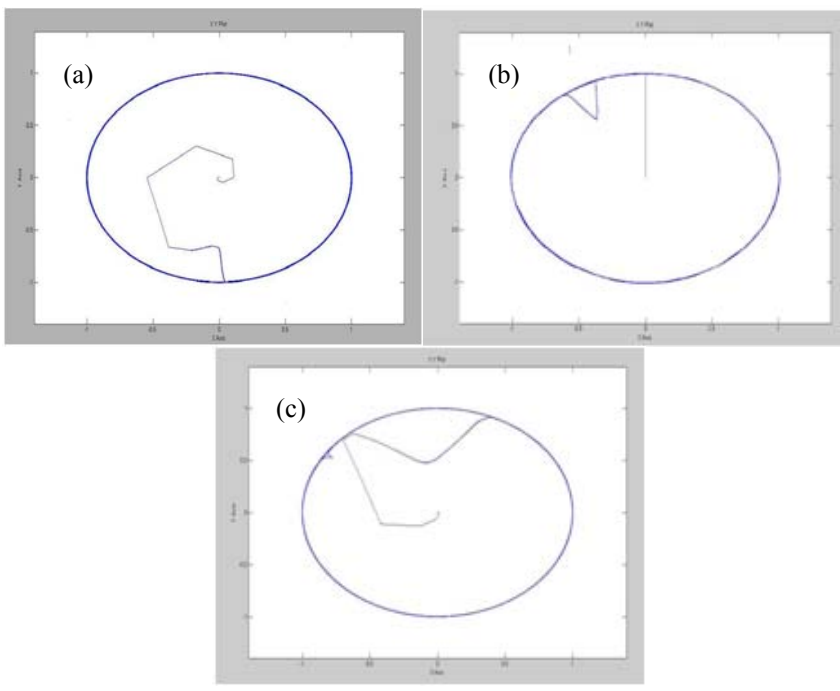

Fig. 4. (a) xy plot of d-q flux (2LI STDTC) (b) xy plot of d-q flux (2LI FRDTC) (c) xy plot of d-q flux in (3LI STDTC)

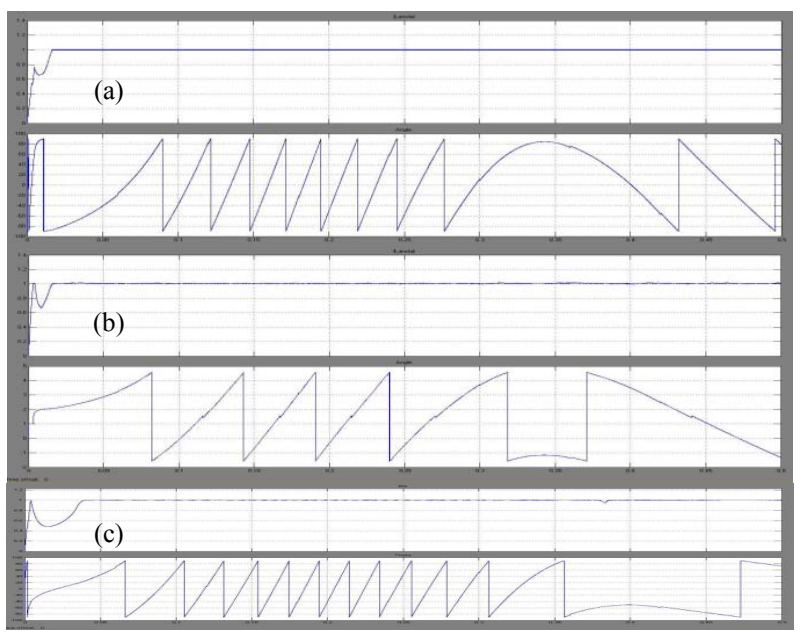

Fig. 5. (a) abs flux and angle vs time (2LI STDTC) (b) abs flux and angle vs time (2LI FRDTC) (c) abs flux and angle vs time (3LI STDTC)

Figure 9 shows the superimposed torque with its respective command value. The fast response of torque to the command value is noted in all three cases. Rising torque in forward and reverse motoring during $30 \%$ to $60 \%$ rise mode has been considered as instance in Figures 9 and 10. As seen in Table II, a faster response of change in torque has been observed in FRDTC based 2-level inverter (0.12 milli-secs). In comparison, the Fuzzy Rule based DTC scheme provides faster response but ripples in torque increase. Total Harmonic Distortion (THD) is measured using the FFT tool. It is observed that THD in the STDTC scheme, applied with 3 level inverter, is lowest among the three schemes studied but torque response to command is quite slow. The air gap has been divided into six and twelve sectors for different approaches. Figure 11 shows both postulations. The dwelling position of air gap flux in different sectors has been traced out in forward and reverse mode operation. Accordingly the development of sectors has also been modified corresponding to the mode of motor operation.

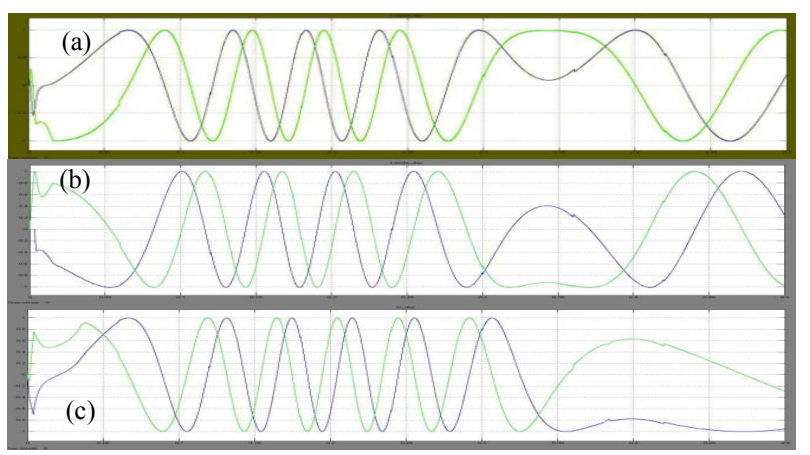

Fig. 6. (a) dq flux vs time (2LI STDTC) (b) dq flux vs time (2LI FRDTC) (c) dq flux vs time (3LI STDTC)

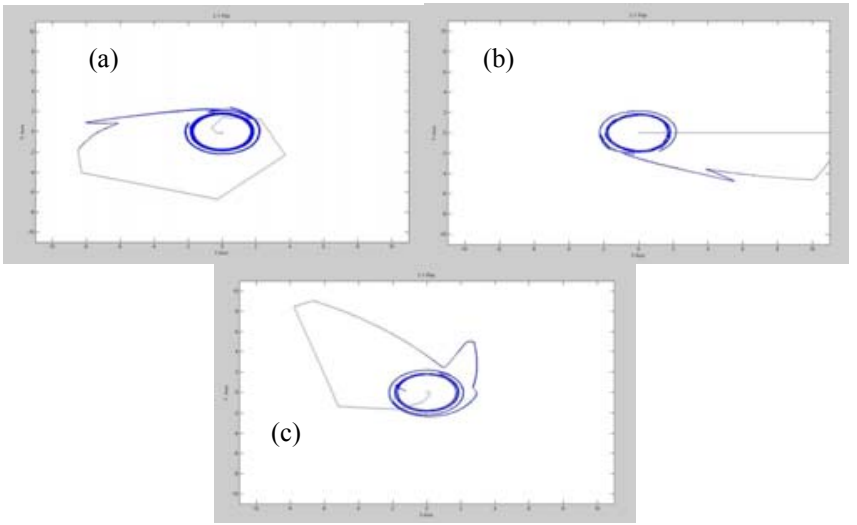

Fig. 7. (a) xy plot of dq current in 2LI STDTC (b) xy plot of dq current in 2LI FRDTC (c). xy plot of dq current in 3LI STDTC

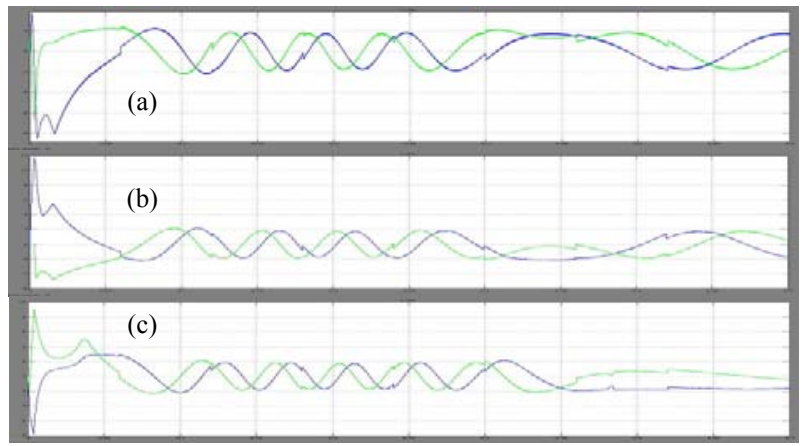

Fig. 8. (a) dq current vs time in 2LI STDTC (b) dq current vs time in 2LI FRDTC (c) dq current vs time in 3LI STDTC 


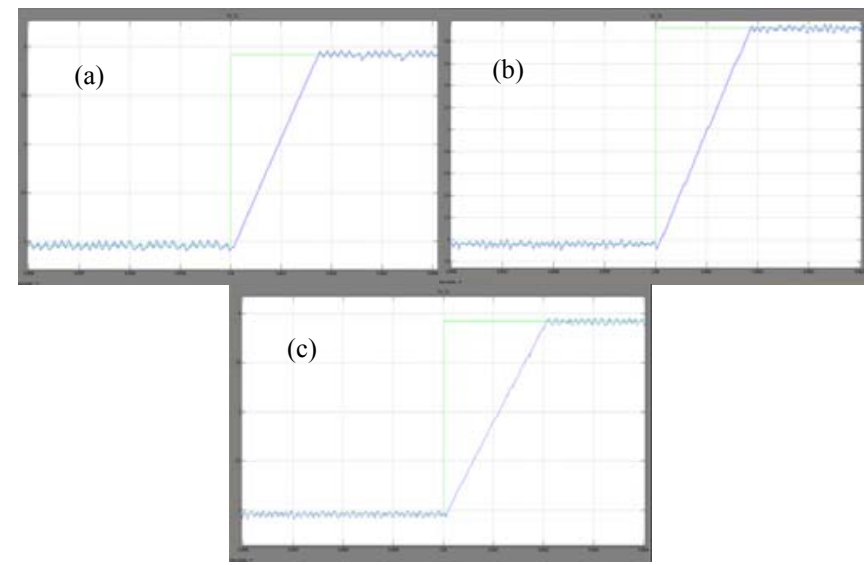

Fig. 9. (a) rising torque vs time at forward motoring (2LISTDTC) (b) rising torque vs time at forward motoring (2LIFRDTC) (c) rising torque vs time at forward motoring (3LISTDTC)

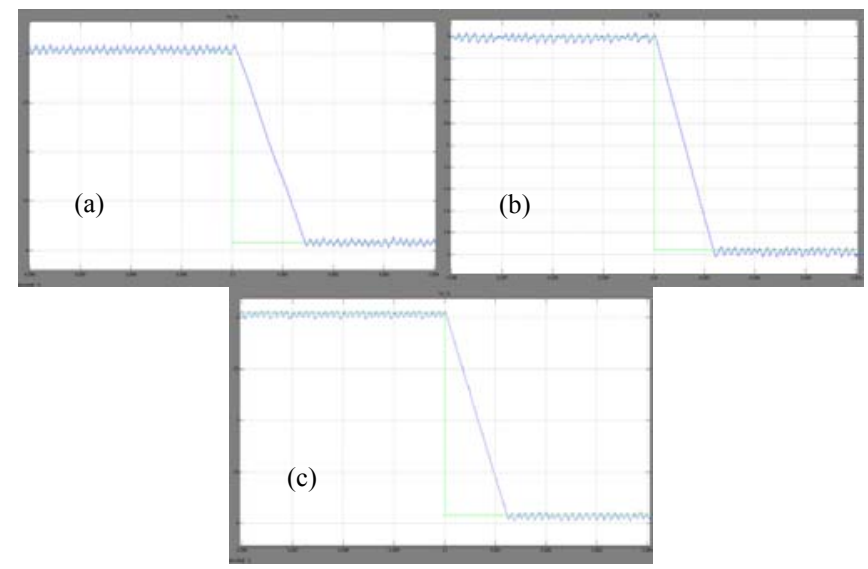

Fig. 10. (a) rising torque vs time at reverse motoring (2LISTDTC ) (b) rising torque vs time at reverse motoring (2LIFRDTC) (c) rising torque vs time at reverse motoring (3LISTDTC)

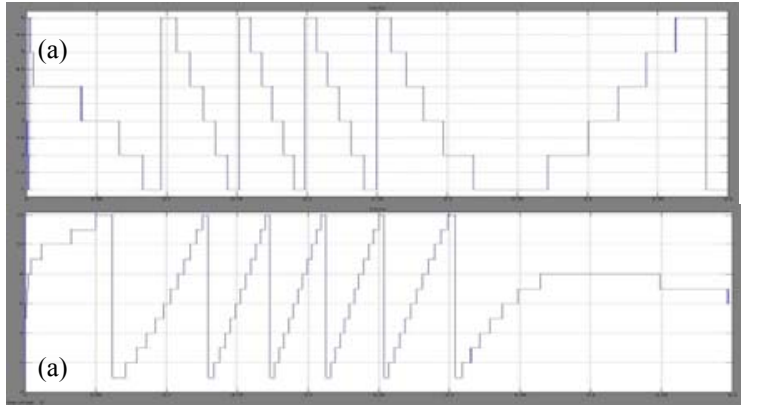

Fig. 11. (a) six sector in two quadrant operation (b) twelve sector in two quadrant operation

\section{CONCLUSION}

The DTC scheme has been studied using three strategies in this paper. The classical ST-DTC scheme has been implemented with the logical simulation of low cost analog circuits for 2-level and 3-level inverters. The same inverters have been simulated using fuzzy logic. The faster torque response is documented in the FR-DTC schemes (in comparison to the ST-DTC scheme) but the THD values are also larger. In conclusion, to implement a low cost DTC scheme with the least harmonic distortion, the implementation with a diode clamped 3-level inverter seems preferable.

TABLE II. TORQUE PERFORMANCE \& SWITCHING STRATEGIES

\begin{tabular}{|c|c|c|c|}
\hline & $\begin{array}{c}\text { 2 LI ST- } \\
\text { DTC }\end{array}$ & $\begin{array}{c}\text { 2LI FR- } \\
\text { DTC }\end{array}$ & $\begin{array}{c}\text { 3LI ST- } \\
\text { DTC }\end{array}$ \\
\hline $\begin{array}{c}\text { 0.3T to 0.6T rise in Forward } \\
\text { motoring (m-s) }\end{array}$ & 0.17 & 0.16 & 0.22 \\
\hline $\begin{array}{c}\text { 0.3T to 0.6T rise in Reverse } \\
\text { motoring (m-s) }\end{array}$ & 0.15 & 0.12 & 0.15 \\
\hline \% THD in Torque & 106.52 & 117.61 & 46.13 \\
\hline
\end{tabular}

REFERENCES

[1] S F. Blaschke, "The principle of field-orientation as applied to the trans vector closed-loop control system for rotating-field machines", Siemens Review, Vol. 34, pp. 217-220, 1972

[2] M. Depenbrock, "Direct self-control (DSC) of inverter-fed induction Machine", IEEE Transactions on Power Electronics, Vol. 3, No. 4, pp. 420-429, 1988

[3] I. Takahashi, Y. Ohmori, "High performance direct torque control of an induction motor", IEEE Transactions on Industry Applications, Vol. 25, No. 2, pp. 257-264, 1989

[4] T. G. Habetler, F. Profumo, M. Pastorelli, L. M. Tolbert, "Direct torque control of induction machines using space vector modulation", IEEE Transactions on Industry Applications, Vol. 28, No. 5, pp. 1045-1053, 1992

[5] U. Baader, M. Depenbrock, G. Gierse, "Direct self control (DSC) of inverter fed induction machine: a basis for speed control without speed measurement", IEEE Transactions on Industry Applications, Vol. 28, No. 3, pp. 581-588, 1992

[6] D. Casadei, G. Serra, A. Tani, "Implementation of a direct torque control algorithm for induction motors based on discrete space vector modulation", IEEE Transactions on Power Electronics, Vol. 15, No. 4, pp. 769-777, 2000

[7] D. Casadei, F. Profumo, G. Serra, A. Tani, "FOC and DTC: two viable schemes for induction motors torque control", IEEE Transactions on Power Electronics, Vol.17, No. 5, pp. 779-787, 2002

[8] F. Zidani, R. Nait Said, "Direct torque control of induction motor with fuzzy minimization torque ripple", Journal of Electrical Engineering, Vol. 56, No. 7-8, pp. 183-188, 2005

[9] F. Zidani, D. Diallo, M. E. H. Benbouzid, R. Nait Said, "Direct torque control of induction motor with fuzzy stator resistance adaptation", IEEE Transaction on Energy Conversion, Vol. 21, No. 2, pp. 619-621, 2006

[10] M. Vasudevan, R. Arumugam, "High performance adaptive intelligent direct torque control schemes for induction motor drives", KMITL Science and Technology Journal, Vol. 5, No. 3, pp. 559-576, 2005

[11] B. P. Panigrahi, D. Prasad, S. SenGupta, "Digital simulation and PC based implementation of switching table based direct torque control of induction motor drive", IIT Conference, Kharagpur, pp. 1-6, 2005

[12] B. P. Panigrahi, D. Prasad, S. SenGupta, "A simple hardware realization of switching table based direct torque control of induction motor", Electric Power Systems Research, Vol. 77, No. 2, pp. 181-190, 2007

[13] D. Prasad, B. P. Panigrahi, S. SenGupta, "Digital simulation and hardware implementation of a simple scheme for direct torque control of induction motor", Energy Conversion and Management, Vol. 49, No. 4, pp. $687-697,2008$

[14] P. R. Tripathy, B. P. Panigrahi, "Simulation study on DTC based induction motor drives using MATLAB", IEEE Proceedings of INDICON, India, Vol. 1, pp. 65-68, 2008

[15] P. R. Tripathy, B. P. Panigrahi, "Simulation studies on switching table based DTC and fuzzy rule based DTC for three-phase squirrel cage induction motor", Engineering, Technology \& Applied Science Research, Vol. 2, No. 1, pp. 162-166, 2012 